\title{
Plasma and nitrides: application to the nitriding of titanium
}

\author{
A. GICOUEL, N. LAIDANI, P. SAILLARD, J. AMOUROUX
}

Ecole Nationale Supérieure de Chimie de Paris Laboratoire des Réacteurs Chimiques en Phase Plasma 11 rue Pierre et Marie Curie, 75231 PARIS Cedex 05 FRANCE

\begin{abstract}
Plasmas technologies are known to be very efficient for surface treatments, and this is the case for the production of titanium nitride. We demonstrate an increase of the kinetics due to the plasma in a diffusion reactor. Different growth laws have been obtained, they depend on the substrate surface state, on the temperature and on the active species flux. The competition between nitrogen atoms recombination and diffusion processes is also discussed.
\end{abstract}

\section{INTRODUCTION}

Due to its numerous qualities, titanium nitride is an appropriate candidate for many applications. Beyond its low weight $\left(5.43 \mathrm{~g} / \mathrm{cm}^{3}\right)$, one can quote its good electrical $(\rho=21.7 \mu \Omega . \mathrm{cm}$ at $20^{\circ} \mathrm{C}$ ), thermal, mechanical and chemical properties (ref. 1,2). Moreover, it is sought for its high hardness ( 800 to $2600 \mathrm{~kg} / \mathrm{mm}^{2}$ ) (ref. 3), its good friction coefficient ( 0.5 for the TiN-stainless steel system), its excellent abrasive resistance, its relatively low Young modulus (100-250 GPa) and for its gold color; all these properties depend strongly on fabrication processes. Due to these properties, titanium nitride will be used as a coating for cutting tools or as an anticorrosive coating for turbines as in aerospatial industries (low weight) or it will find application in a medical field (prothesis) because of its biocompatibility (ref. 4). In microelectronics instrumentation, titanium nitride is used for its electrical characteristics and for its diffusion barrier properties (Al/TiN/TiSi2 $/ \mathrm{Si}$ ) (ref. 5,6,7).

The physical and chemical vapor deposition techniques and diffusion techniques as well, have been shown to be very successful. However, in both cases, plasmas have been seen to enhance the nitride formation rate. In the first part of this paper, the main results obtained by using chemical and physical vapor deposition techniques will be presented. The second part will be focused on the diffusion elementary processes in order to get a better understanding of the nitride growing laws as a function of the reactor key parameters. In particular, we want to discuss the role of neutrals and charged species from energetic and mass transfers point of view. We will also take attention to the role of the surface state as it can greatly modify the involved mechanisms.

\section{TITANIUM NITRIDE PRODUCTION METHODS}

The nitridation of metallic surfaces using plasma techniques has already reached an industrial stage. Two major methods are usually developped for the titanium nitride synthesis : in the first process, TiN molecules are formed in gaseous phase and are then deposited onto a substrate, as in the second one, nitrogen atoms diffuse into the titanium matrix. TiN deposition is based on two techniques: PVD (Physical Vapor Deposition) (ref. 8) and CVD (Chemical Vapor Deposition) (ref. 9). In both techniques, titanium reacts in the gaseous phase with a nitrogen containing compound to form TiN. The formation of the TiN molecules can occur either in the gaseous phase, or on the surface. The first mechanism involves excited states of both titanium atoms and nitrogen molecules (ref.10), while the second one involves a recombination reaction between the $\mathrm{Ti}$ and $\mathrm{N}$ atoms on the surface. The properties of the films are dependant on the involved mechanism. Plasma Assisted Physical Vapor Deposition (PAPVD) or ionic PVD allows us to deposit layers for temperatures ranging between 200 and $500^{\circ} \mathrm{C}$. Titanium production in the gaseous phase is realized either by evaporation of a titanium target by Joule effect or electron beam (reactive evaporation), either by target sputtering by means of energetic ions. The most encountered reactive gases are mixtures such as Ar- $\mathrm{N}_{2}, \mathrm{Ar}-\mathrm{N}_{2}-\mathrm{H}_{2}$ or Ar- $\mathrm{NH}_{3}$ and the pressure ranges between $10^{-4}$ and $10^{-2}$ Torrs, according to the process. The substrate is often negatively biased; this enables a permanent cleaning 
of the substrate. However, the importance of the substrate bias has an influence on the properties of the formed layers. In Chemical Vapor Deposition, titanium atoms are provided in the gaseous phase by the craking of $\mathrm{TiCl}_{4}$, either by thermal process or by electron impact (Plasma Assisted CVD). Working pressures range from 0.1 to a few millibars and substrate temperatures lie between 400 to $850^{\circ} \mathrm{C}$, for the Plasma Assisted CVD techniques, and between 1000 and $1200{ }^{\circ} \mathrm{C}$ in the case of the thermal process. Titanium nitride layers up to $20 \mu \mathrm{m}$ thick, with a typical hardness of $2600 \mathrm{Kgf} / \mathrm{mm}^{2}$ have been obtained using these techniques (ref.11). However, the layers were chloride containing, thus their anticorrosive properties were limited. Therefore, the PVD and PAPVD techniques would be preferred for metallurgical applications. However, even though these techniques have been extensively developped and studied, diffusion nitridation using a low pressure discharge has some advantages and it is still widely studied (ref. 12,13,14,15). This process allows the formation of an homogeneous nitride layer whatever the shape of the substrate is. These techniques involve nitrogen transportation into the substrate; however, elementary processes are not clearly understood, but likely they depend on the type of discharge and on the reactor working conditions.

\section{DIFFUSION MECHANISMS}

The phase diagram (figure 1) (ref. 2,16,17) reveals the great solubility of nitrogen in titanium for high temperature ( 22 to $25 \%$ ) and even for lower temperature. For a temperature lower than $880^{\circ} \mathrm{C}$, titanium nitride formation requires at least $33 \% \mathrm{~N}$ atoms to obtain the $\mathrm{TiN}_{0.42}$ compound. Non stoechiometric nitrides and nitrogen solid solution in titanium matrix will then be expected (ref.18), and in fact, $\delta-\mathrm{TiN}, \varepsilon-\mathrm{Ti}_{2} \mathrm{~N}$ and $\alpha-\mathrm{Ti}(\mathrm{N})$ have all been detected in our laboratory.

Chemical potential gradient- The first step for nitride formation involves nitrogen adsorption on metallic sites. However, nitrogen concentration profiles in the metal will be governed by diffusion laws depending on the crystallization state of the metal and on the temperature. For an hexagonal compact monocrystal ( $\mathrm{Ti})$, nitrogen diffusion $\left(\mathrm{r}_{\mathrm{N}}=0.92 \AA\right)$ will take place via the octahedral cavities $(r=0.6 \AA)$ rather than the tetrahedral ones $(r=0.33 \AA)$, because of their relative dimensions. As nitrogen is larger than the octahedral cavities, nitridation will induce an expension of the lattice, and the jump of a nitrogen atom from a cavity to another needs the displacement of the titanium atoms. Then, nitrogen diffusion requires an activation energetic barrier to be crossed over. Diffusion coefficient values from litterature have to be considered with caution, since they can vary substantially depending of the authors. For nitrogen diffusion in the $\alpha$ phase at $1000^{\circ} \mathrm{C}$, a value of about $0.12 \exp (-45200 / 1.98 \mathrm{~T}) \mathrm{cm}^{2} / \mathrm{s}$ has been found (ref. 19). When diffusion occurs in a polycrystalline substrate, diffusion mostly proceeds along the grain boundaries. This lowers the activation barrier and enhances the diffusion coefficient (ref. 20). Due to the nitrogen concentration profiles into the matrix, the nitride formation will first take place on the substrate surface since the $33 \%$ minimum nitrogen content will be reached first at this position. Once this amount, the crystallic lattice state changes towards the centred faces cubic ( $\mathrm{NaCl}$ type crystal). As a few titanium nitride layers are formed, nitrogen must diffuse through these layers for the nitridation process to go on. Nitrogen diffusion coefficients in the titanium nitride layers ( $\delta$ and $\varepsilon$ phases) are not precisely known but they are continously varying with the nitride stoechiometry since incorporated nitrogen atoms in the titanium matrix are occupying the octahedral sites. Therefore, titanium nitride constitutes a diffusion barrier for nitrogen relatively to the metallic titanium, and diffusion coefficients in the titanium nitride are expected to be lower than those in the metal $\left(5.410^{-3} \mathrm{exp}(-\right.$ $52000 / 1.98 \mathrm{~T})$ and $3.510^{-4} \exp (-41000 / 1.98 \mathrm{~T})$, respectively for the $\delta$ phase and the $\varepsilon$ phase, at around $1000^{\circ} \mathrm{C}$ ) (ref.19). According to the diffusion mechanism, the expected layers growth law whould follow a (time) $1 / 2$ variation, derived from the second Fick's law.

Electric field and temperature gradient- Diffusion of species in solids can be ruled by phenomena other than chemical potential field. In a biased ionic type material, positive charges move towards the negative terminal and vice versa. In the same way, a high temperature gradient between the ends of a metallic rod, an extremity of which contains an interstitial element, provokes species transport phenomena. The diffusion species will then be ruled by a more complex equation : $J=-D d c / d t-D\left(Q^{*} C / R T^{2}\right) d T / d x-D(q C / k T) d \Phi / d x$, where $Q^{*}$ is the heat transport, $d T / d x$ the temperature gradient, $q$ the species charge and $d \Phi / d x$ the electric field gradient (ref. 20 ). In that case, layer growth does not correspond to a (time) ${ }^{1 / 2}$ dependance equation, but either to a (time) ${ }^{1 / 3}$ or a Ln(time) dependance equation. In our experimental conditions, a temperature gradient is not expected since titanium and titanium nitride are both good thermal conductors, moreover $Q^{*}$ heat transport are low, that makes $D\left(Q^{*} C / R^{2}\right)$ low relative to $D$. On the contrary, assisted diffusion 
under electric field (usually called migration) is reasonably expected. In fact, oxides and nitrides have ionic characteristics due to the $\delta^{+}-\delta^{-}$polarized metal-atom bonds. But, considering that electrical conductivity of titanium nitride is higher than that of metallic titanium, a charge accumulation on one side of the nitrided sample seems unlikely. On the contrary, this phenomenom is highly probable for semiconductive titanium oxides, which are generally present on titanium surfaces.

\section{ROLE OF THE PLASMA}

\section{Production of the active species}

From above, the nitridation kinetics are controlled by diffusion phenomena, depending on the surface temperature, the nitrogen concentration gradient and likely the presence of a superficial electric field. Since a high density of chemisorbed nitrogen atoms is required, the superficial nitrogen concentration will be an important parameter, which should actually depends on the chemical reactivity of the gaseous phase. In general, dissociative chemisorption on the surface sites requires an activation energy and is substrate temperature dependant. Plasma techniques can then be hepful since plasma is generating dissociated species into the gaseous phase, which do not require activation energy for chemisorption. Thus, the choice of the nitriding gas is very important. Nitrogen molecules require a high dissociation energy and under the general conditions (vacuum limits, gas) nitrogen atmosphere contains oxygen, which makes nitrogen an unattractive nitriding gas. Therefore, mixtures such as $\mathrm{N}_{2}-\mathrm{H}_{2}, \mathrm{~N}_{2}-\mathrm{H}_{2}-\mathrm{Ar}$ or $\mathrm{NH}_{3}$ are largely preferred, because of the reductive properties of hydrogen. The reducting action of hydrogen both in the gaseous phase (oxygen contamination) and on the substrate (adsorption sites increase), leads to an important increase of the nitridation /oxydation rates. Hydrogen has also been demonstrated to increase the electron mean velocity and to produce $\mathrm{NH}$ by reaction with vibrationally excited nitrogen molecules in plasmas (ref. 21). In plasmas, ions and vibrationally excited molecules are also produced. They do not need chemisorption activation energy (or a small one), they are then very active for nitriding process. Hudis et al (ref. 22) have established that ionic nitriding is very efficient, while A. Ricard and M. Pealat (ref.23, 24) have found out that nitridation can be achieved in the complete absence of ions, once the nitrogen atom concentration is high enough. We should notice that nitridation can be achieved both in glow discharge and in post discharge as nitriding species (excluding ions), and in particular atoms, have low recombination coefficients on silica or glass reactor walls. Thus, they can be transported, under low pressure conditions, far from the plasma source with no substantial concentration decrease.

\section{Energy transfer}

Energy transfer is an important aspect for we have seen that as nitriding species are created in the plasma phase, the overall kinetics will depend on substrate temperature. Due to the numerous different species produced in the plasma phase, the overall transfer quantification is difficult to estimate (ref. 25). Indeed, for the same chemical system, energy transfer for a single species depends on the type of energy mode which is considered. In fact, the accomodation of each mode of energy depends, on one hand, on the matching between the excitation type of the molecule and the substrate network and, on the other hand on the residence time of the species on the surface

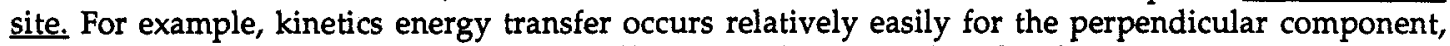
and the corresponding accomodation coefficient is close to unity. On the contrary, accomodation coefficient for rotational and vibrational energies is much lower $(\gamma=0.1-0.4)$. In the case of ions, potential and kinetics energies can be transferred. If the substrate is negatively biased, the amount of energy provided by the ions should be important. Whenever the treatment occurs in glow discharge or post discharge, the energy released during radicals and atoms recombination reactions has to be taken into consideration. As far as metallic catalytic substrates are concerned (involving Eley-Rideal mechanism for recombination processes), the accomodation coefficient remains relatively low $\left(10^{-4}\right.$ to $10^{-3}$ ); however, for a relatively high atomic concentration, heating due to this process can be appreciable, and therefore should not be neglicted. In conclusion for a discharge treatment, the substrate heating is due to the action of the ions, of the hot neutrals (vibration, rotation, kinetics), and of the atoms and radicals recombination processes, while for a post discharge, it is mainly due to the surface recombination reactions and to the neutral species energy contained (vibration, rotation and kinetics) after the relaxation processes. If these parameters are not taken into account, the substrate temperature might be much higher than that selected with a furnace. Moreover, the substrate temperature, at the steady state, should vary during treatment even for a constant heating source since it strongly depends on the surface emissivity which is changing during the treatment. 


\section{TITANIUM NITRIDATION UNDER $\mathrm{NH}_{3}$ LOW PRESSURE PLASMA}

\subsection{Experimental set up}

Nitridation of $5 \mathrm{~cm}^{2}$ and $0.25 \mathrm{~mm}$ thick titanium target (purity : $99.995 \%$ ) has been performed in a $40 \mathrm{~cm}$ long and $4.5 \mathrm{~cm}$ diameter silica reactor. The discharge was created by either a 40 $\mathrm{MHz}$ or a $13.56 \mathrm{MHz}$ generator, delivering power up to $1 \mathrm{~kW}$, through inductive coils. The working pressure was 10 to $30 \mathrm{mbars}$ and the $\mathrm{NH}_{3}$ flow rate ranged from 0.2 to $0.6 \mathrm{l} / \mathrm{min}$. The substrate was held perpendicularly to the flux as illustrated on figure 2 . Sample temperatures were varying from 500 to $850^{\circ} \mathrm{C}$. Titanium samples were analyzed by means of RBS, NRA, ESCA and Xrays, to determine chemical composition, both on the surface and into the bulk. Hydrogen profiles in the bulk have been obtained by SDL. Electrical characteristics of electrolyte-titanium or electrolytenitrided titanium have been achieved by photoelectrical means. The kinetics study has been performed by measuring the increase of the sample weight by gravitometry. The spectroscopic analysis of the plasma has been performed on electronic excited state of the molecules, in particular

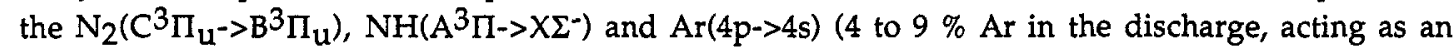
actinometer) transitions have been recorded in order to get the vibrational and rotational temperatures of the $C^{3} \Pi_{u}$ electronic state of nitrogen as well as to follow the relative production of $\mathrm{N}_{2}(\mathrm{X})$ along the reactor. Vapor phase chromatography and mass spectrometry were used to determine the out gas chemical composition.

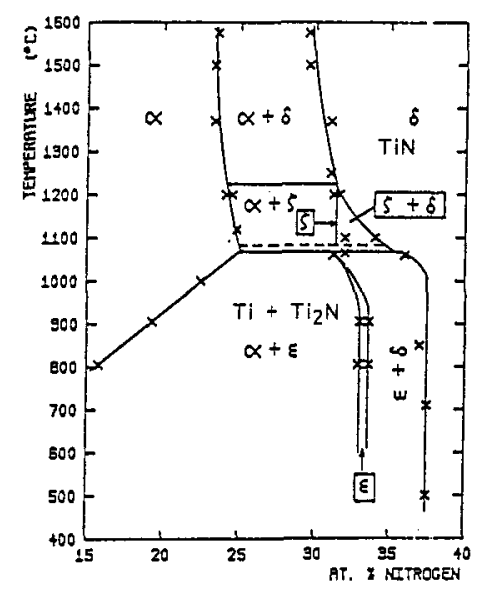

Figure 1: Ti, $\mathrm{N}$ phase diagram after ref. 16.

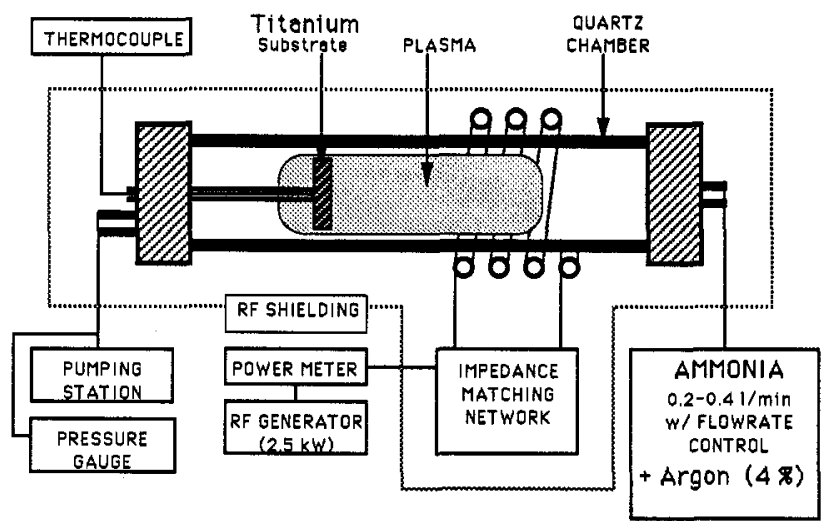

Figure 2: Reactor set up.

\subsection{Mass and energy transfers. Nitridation kinetics}

\section{Superficial and depth analysis}

ESCA pointed out the presence of a $\mathrm{TiO}_{2}$ surface oxide for all the untreated titanium samples. An $\mathrm{NH}_{3}$ plasma treatment leads to the $\mathrm{TiO}_{2}$ oxide disappearance ( $\mathrm{Ti}_{2 \mathrm{p} 3 / 2}: 458.7 \mathrm{eV}$ ) and to the formation of both titanium nitride $\operatorname{TiN}(455.2 \mathrm{eV})$ and oxinitride $(\mathrm{Ti}, \mathrm{O}, \mathrm{N})(458 \mathrm{eV})$. Recording $\mathrm{N}_{1 \mathrm{~s}}$ binding energies reveals the presence of two peaks at 396 and $396.8 \mathrm{eV}$ corresponding respectively to the oxinitride and nitride. After treatment, $\mathrm{O}_{1 \mathrm{~s}}$ binding energy is displaced and split from $530.7 \mathrm{eV}\left(\mathrm{TiO}_{2}\right)$ to $529.9 \mathrm{eV}(\mathrm{Ti}, \mathrm{O}, \mathrm{N})$ and a small peak at $532.2 \mathrm{eV}$ probably due to $\mathrm{OH}$ groups or chemisorbed oxygen atoms. The evolution of the nitride/oxinitride peaks height ratio has been studied as a function of pressure, coil-sample distance, and input power. Results are gathered in table 1 and point out that nitride /oxinitride ratio is increasing as the pressure or the coil-titanium distance is decreasing and as the power is increasing. This suggests that nitride compared to oxinitride formation is favored when the ions density and energy are increasing and/or the dissociated species density is increasing. Indeed, as pressure is lowered, the electron mean free path is increased and consequently, electron energy is enhanced; moreover, as input power is increased, the electron energy and density are enhanced as well. Thus, decreasing pressure or increasing power enhances plasma energetic density and leads to a plasma containing more dissociated species and more energetic ions. As the titanium-coil is shortened, energetic density is also enhanced, but residence time is decreased, leading to a decrease of the $\mathrm{NH}_{3}$ decomposition rate. Thus, although it is not easy to distinguish ions and radicals (or atoms) actions when pressure or power are changed, in 
the case of the shortening of coil-sample distance, we can assert that energetic density increase only leads to ions energy and/or density enhancement. In this case, we can quote that the increase of the nitride/oxinitride production ratio, is due to the action of the ions on the surface.

Analyzing treated samples by means of RBS and SDL enabled us to know depth modifications. Moreover from spectra simulations, the thickness of the different formed layers can be estimated. Profiles corresponding to treatments performed at $650^{\circ} \mathrm{C}$ and $850^{\circ} \mathrm{C}$ are presented on figure 3. Titanium and hydrogen profiles from SDL are illustrated on figure 4. The maximum hydrogen concentration was always located at the $\mathrm{TiN} / \mathrm{Ti}_{2} \mathrm{~N}$ interface.

NRA analysis enabled us to demonstrate the effect of the plasma on nitriding. For a given temperature, the higher the discharge power is, the higher the amount of nitrogen atoms incorporated into the substrate is (table 2).

TABLE 1: Nitride/oxinitride peak heights ratios for the Ti2p3/2 and N1s elements as a function of pres sure, discharge power and titanium/coils distance.

\begin{tabular}{|l|l|l|}
\hline Element & Ti 2p3/2 & $\mathrm{N}_{1 \mathrm{~s}}$ \\
\hline Ratio & TiN/Ti.O.N] & TiN/[Ti.O.N_ \\
\hline
\end{tabular}

\begin{tabular}{|l|l|l|}
\hline Pressure infl. & $\mathrm{PI}=900 \mathrm{~W}$ & $\mathrm{~d}=2.5 \mathrm{~cm}$ \\
\hline
\end{tabular}

\begin{tabular}{|c|c|c|}
\hline 7 mbars & 1.21 & 11.5 \\
\hline 9.5 mbars & 1.1 & 4.83 \\
\hline 13 mbars & 0.88 & 0.6 \\
\hline 40 mbars & 0.35 & 0.4 \\
\hline
\end{tabular}

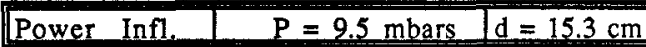

\begin{tabular}{|c|c|c|}
\hline $1.5 \mathrm{~kW}$ & 0.91 & 3.35 \\
\hline $2 \mathrm{~kW}$ & 0.98 & 4.44 \\
\hline
\end{tabular}

\begin{tabular}{|l|l|l|}
\hline distance Infl. & $P=9.5$ mbars & $P I=900 \mathrm{~W}$ \\
\hline
\end{tabular}

\begin{tabular}{|c|c|c|}
\hline $2.5 \mathrm{~cm}$ & 1.1 & 4.83 \\
\hline $14.5 \mathrm{~cm}$ & 0.89 & 1.45 \\
\hline $16 \mathrm{~cm}$ & 0.81 & 0.72 \\
\hline
\end{tabular}

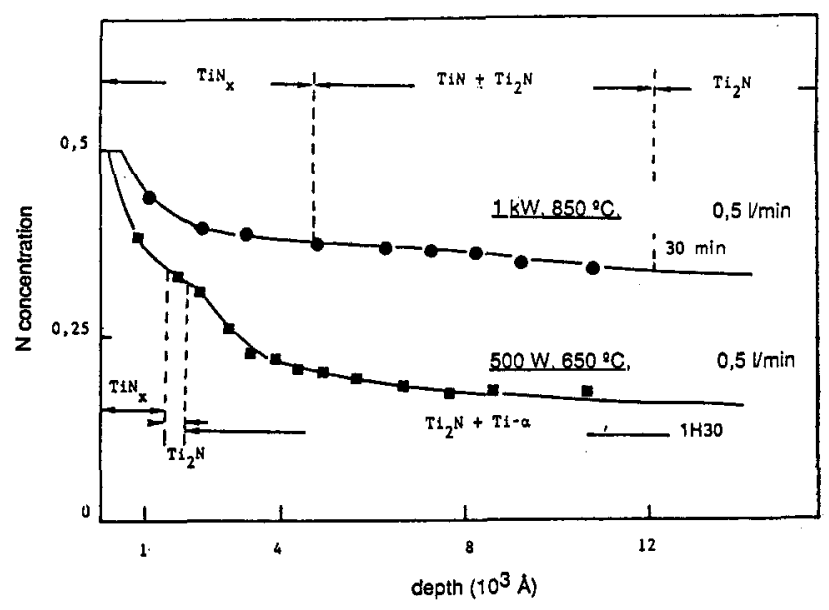

Figure 3: Resulting computing nitrogen profiles into the titanium samples treated by an $\mathrm{NH}_{3}$ plasma, for two experiments:

$$
\text { - } P I=500 W, T=650^{\circ} \mathrm{C}, t=1.5 \text { hour }
$$

- $P I=1 \mathrm{~kW}, \mathrm{~T}=850^{\circ} \mathrm{C}, \mathrm{t}=0.5 \mathrm{~h}$

$\mathrm{P}=17.5 \mathrm{mbars}, \mathrm{D}=0.5 \mathrm{l} / \mathrm{min}, \mathrm{d}=12.5 \mathrm{~cm}$.

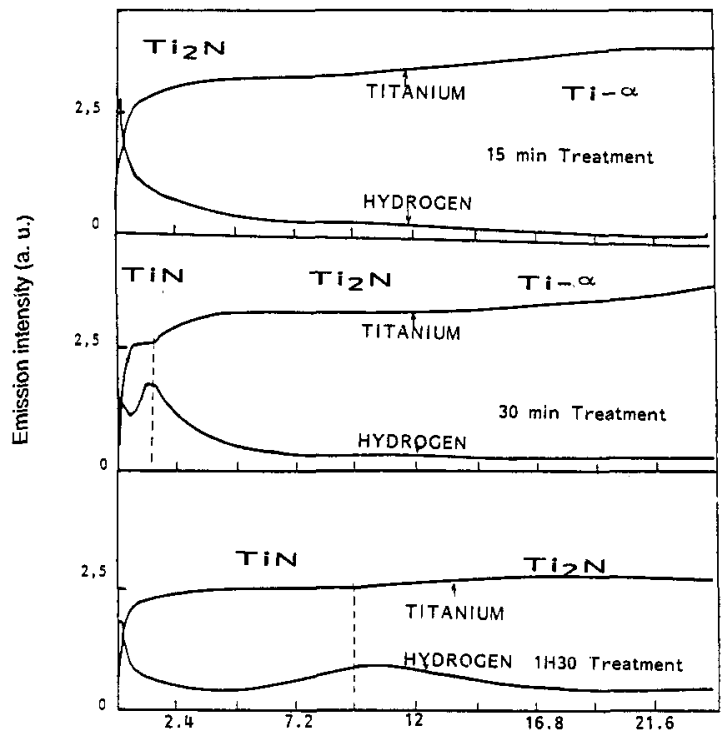

Erosion time (s)

Figure 4: Titanium and hydrogen profiles into the samples treated by a $\mathrm{NH}_{3}$ plasma as a function of treatment time. $\mathrm{P}=17.5$ mbars, $\mathrm{PI}=1 \mathrm{~kW}, \mathrm{D}=0,5 \mathrm{l} / \mathrm{min}$.

Table 2 : Incorporated nitrogen atoms $\left(10^{17} \mathrm{atom} / \mathrm{cm}^{2}\right)$ into the titanium matrix as a function of the power discharge for two substrate temperatures.

$\overline{\text { Power }}(\bar{W})$
$\overline{\mathrm{T}}=650^{\circ} \mathrm{C}$
$\mathrm{T}=850^{\circ} \mathrm{C}$




\section{Nitride layer growth laws}

Influence of the flow rate- Comparing sample weight increases as a function of treatment time at a constant power $(500 \mathrm{~W})$ and an almost constant temperature $\left(600^{\circ} \mathrm{C}\right)$ for two different flow rates $(0.2$ and $0.51 / \mathrm{min}$ ) points out the role of the nitriding species flux on nitridation mechanisms (figure $5 a)$. Indeed, for a $0.21 / \mathrm{min}$ flow rate, the nitridation kinetics can be described by a linear law, indicating that the process is controlled by the chemical reaction on the surface. In others words, the nitriding species flux impinging the surface is the limiting step for the process. On the contrary, for a $0.5 \mathrm{l} / \mathrm{min}$ flow rate, the nitriding kinetics can be described as a $\operatorname{Ln}(1+\mathrm{t})$ law. Then, the species flux impinging the surface is high enough and the nitridation process is controlled by the nitrogen transport into the bulk.
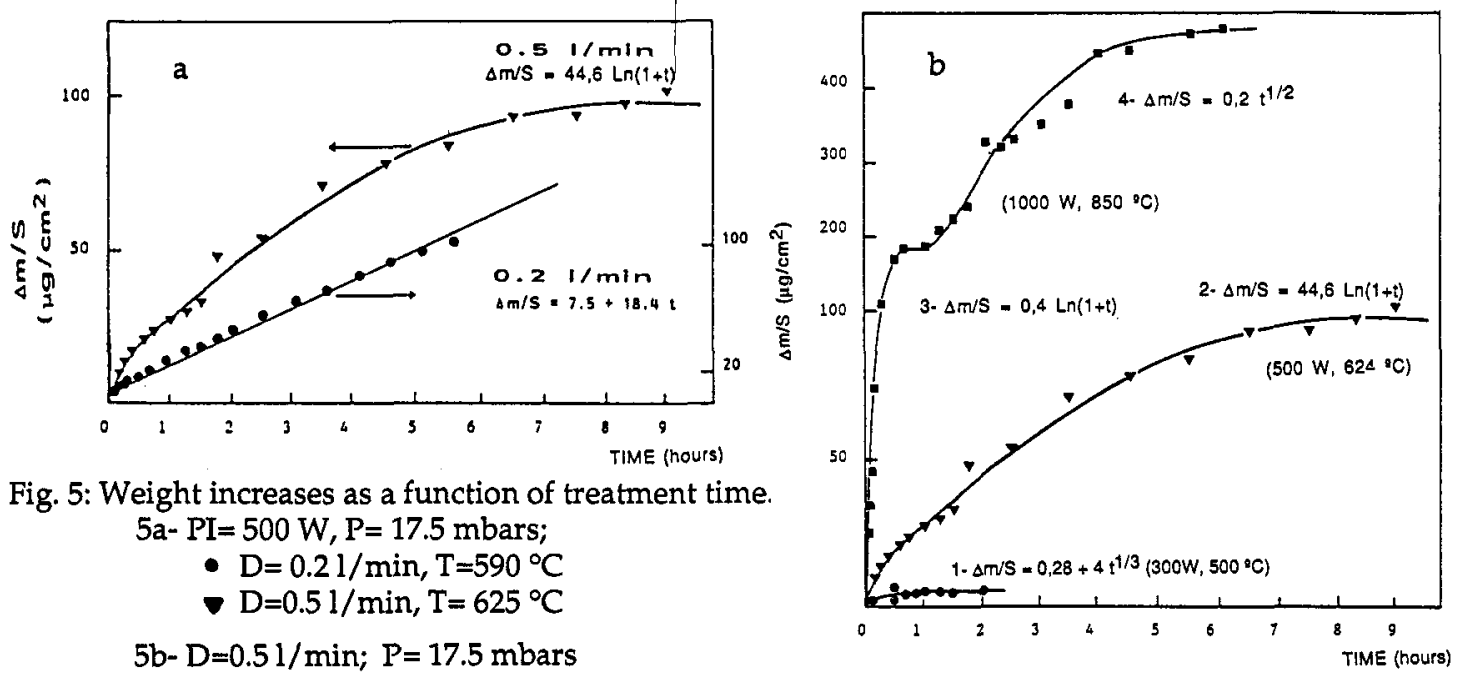

Fig. 5: Weight increases as a function of treatment time. $5 \mathrm{a}-\mathrm{PI}=500 \mathrm{~W}, \mathrm{P}=17.5 \mathrm{mbars}$;

- $\mathrm{D}=0.2 \mathrm{l} / \mathrm{min}, \mathrm{T}=590^{\circ} \mathrm{C}$

- $\mathrm{D}=0.51 / \mathrm{min}, \mathrm{T}=625^{\circ} \mathrm{C}$

$5 \mathrm{~b}-\mathrm{D}=0.51 / \mathrm{min} ; \mathrm{P}=17.5 \mathrm{mbars}$

- $\mathrm{PI}=1 \mathrm{~kW}, \mathrm{~T}=850^{\circ} \mathrm{C}$

- PI $=500 \mathrm{~W}, \mathrm{~T}=625^{\circ} \mathrm{C}$

- $\mathrm{PI}=300 \mathrm{~W}, \mathrm{~T}=500^{\circ} \mathrm{C}$

Temperature Dependance- Selecting flow rate and power in such a way that the nitriding species flux will not be the limitating parameter, the role of the substrate temperature on nitridation mechanisms has been investigated (ref. 26). Experimental results are presented on figure $5 \mathrm{~b}$; the layer growth law is strongly depending on temperature and/or treatment time. Then, at $500^{\circ} \mathrm{C}$, the layer growth follows a $(t)^{1 / 3}$ law, indicating that the growth mechanism is assisted by an electric field according to Wagner theory (ref. 27). At $625^{\circ} \mathrm{C}$, the layer growth is represented by a $\operatorname{Ln}(1+\mathrm{t})$ time dependant law; according to Fehlner and Mott (ref. 28), anionic migration is then responsible for the growth. At $850^{\circ} \mathrm{C}$, two distinct regions can be considered : for treatment time up to 2 hours, a $\operatorname{Ln}(1+\mathrm{t})$ law is observed, and for longer times, the growth is described by a $(t)^{1 / 2}$ law characteristic of a thermochemical diffusion mechanism (concentration gradient) growth. Thus, for low temperatures or short treatment times, nitridation kinetics is governed by the charged species transportation into the titanium matrix. These kinetics laws are characteristics of growth through semiconductive thin layer $(<1000 \AA)$ in the case of cubic laws, and semiconductive very thin layer $(<100 \AA)$ in the case of logarithmic laws. Because of the conductive properties of the titanium nitride, the superficial layer of the substrate has been studied by photoelectrochemical means.

Photochemical results revealed that the untreated surface sample is an n-type semiconductor (anodic photocurrent). A low temperature $\left(500^{\circ} \mathrm{C}\right.$ ) $\mathrm{NH}_{3}$ plasma treatment increases the substrate surface semiconductive properties, as this properties are strongly reduced for higher temperature treatment $\left(625^{\circ} \mathrm{C}\right)$. The corresponding ESCA results pointed out that the $\mathrm{O} / \mathrm{Ti}$ ratio decreases from 1.86 (initial oxide) to 1.6 for $500^{\circ} \mathrm{C}$ treatment and to 1.0 for the $625^{\circ} \mathrm{C}$ treatment (where the corresponding N/O ratio was 1.0). Moreover, interfacial capacitance measurements lead to the sample donor density. Donor density was 3.4 to $1710^{18} \mathrm{~cm}^{-3}$ for untreated sample, $9.210^{18}$ $\mathrm{cm}^{-3}$ for a $500^{\circ} \mathrm{C}$ treated sample and $1.3410^{20} \mathrm{~cm}^{-3}$ for a $625^{\circ} \mathrm{C}$ treated sample (1H30 treatment); the corresponding donor ratio was then 14.5. For these two treated samples, the corresponding sample weight increase ratio was 8 . These results suggest that, for a mild treatment, the surface semiconductive characteristics are slightly enhanced, probably due to the increase of the superficial semiconductive layer thickness. On the opposite, an increase of the nitrogen incorporation rate is responsible for conductive properties of the sample. The growth mechanism is then evolving towards a pure thermochemical diffusion phenomenom. 
Using the RBS analysis, the role of oxygen bulk contamination on nitridation treatment has been deeply investigated, by comparing the nitrogen incorporation for two samples treated in the same $\mathrm{NH}_{3}$ plasma conditions $\left(650^{\circ} \mathrm{C}\right)$, one of them being pretreated in an argon-oxygen (in trace) plasma. A one hour $\mathrm{NH}_{3}$ plasma treatment leads, in the case of the non pretreated sample to the formation of a $2300 \AA$ thick $\operatorname{TiN}_{X}$ layer $(0.1<x<0.5)$ on top of the titanium substrate. Oxygen traces have been found on the overall sample depth. The total nitrogen incorporation was $3.210^{17}$ atoms $/ \mathrm{cm}^{2}$. The oxygen enriched sample exhibits after the ammonia treatment, a $2700 \AA$ thick oxygen free nitride layer, with a $\mathrm{TiN}_{x}(0.3<x<0.5)$ stoechiometry on the top of the $\mathrm{TiO}_{0.1}$ substrate layer. The total nitrogen incorporation was $5.510^{17}$ atoms $/ \mathrm{cm}^{2}$. Oxygen accumulation is found at the $\mathrm{TiN}_{\mathrm{X}} / \mathrm{TiO}_{0.1}$ interface, suggesting that nitrogen repeals oxygen atoms deeper into the substrate, as it is diffusing. The comparison of nitrogen content on both treated substrates seems to confirm the results presented above. Thus, the oxygen presence appears to enhance nitridation kinetics by the addition of a migrational mechanism to the thermochemical diffusional mechanism, due to its $n$ type semiconductive properties.

\subsection{Chemical reactivity and recombination processes}

Emission spectroscopy enabled us to follow the variations of $C^{3} \Pi_{u}$ electronic excited state of nitrogen vibrational and rotational temperatures along the reactor in function of the working parameters. Simultaneously, $\mathrm{NH}_{3}$ decomposition rate measurements lead to the chemical reactivity. of the plasma. A previous work on the correlation between those measurements has demonstrated that, for a pressure varying up to 20 mbars, the chemical reactivity is controlled by electron energy and/or density, residence time and vibrational excitation of the reagent (endothermic limiting step) (ref. 29). For a $20 \mathrm{~ms}$ residence time, $\mathrm{NH}_{3}$ decomposition increases from 22 to $75 \%$ for an increase of 3150 to $4000 \mathrm{~K}$ in the $\mathrm{N}_{2}\left(\mathrm{C}^{3} \Pi_{\mathfrak{u}}\right)$ vibrational temperature, obtained assuming a Bolztmann distribution. Consequently, the nitriding species flux is strongly dependant on pressure, flow rate, residence time, and plasma energetic density, since the impinging active species flux is directly related to the flow rate and the $\mathrm{NH}_{3}$ decomposition rate. As the flow rate was changing from 0.5 to $0.2 \mathrm{l} / \mathrm{min}$, the residence time was increasing by a factor 2.5 , while the dissociation rate was only increasing from 35 to $60 \%$ under the experimental conditions described earlier (low energetic density and low temperature). Then, approximative calculations indicate that the dissociated species flux was higher of a 1.5 factor at $0.51 / \mathrm{min}$ compared to the $0.21 / \mathrm{min}$ flow rate. As referred to the above paragraph, this had lead to a important change in the nitriding mechanisms.

At this point, it should be interesting to determine the main active species for the nitriding process, under these experimental conditions; however, emission spectroscopy does not give access to the ground electronic state species concentrations, excepted in some very peculiar situations. So, even if actinometry at the plasma/surface interface gives rise to a number of problems, the increase of the $\mathrm{N}_{2}(\mathrm{C}->\mathrm{B}) / \mathrm{Ar}(4 \mathrm{p}->4 \mathrm{~s})$ emission intensities ratio at the vicinity of the titanium surface, which has been observed in a previous work (ref. 29), accounts for the production of electronic ground state molecular nitrogen. Moreover, an increase of the vibrational excitation was also observed at the plasma/surface interface. These phenomena were attributed to the catalytic recombination reaction at the surface. Measurements of $\mathrm{NH}$ concentrations were obtained from laser aborption spectroscopy in Stanford University, in collaboration with our Laboratory (Ref. 30). It has been demonstrated that, under these conditions where the substrate was negatively biased relatively to the plasma, the $\mathrm{NH}$ concentration drops sharply as these particles approach the surface. The disappearance of the $N H(X)$ radicals at the interface could not be attributed to NH recombination on the surface (shape of the NH concentration profiles), but rather to their dissociation at the interface, due to the very energetic secondary electrons emitted from the surface (accelerated through the cathodic sheath), after the ions surface neutralization. These results suggest that molecular nitrogen production at the surface occurs more probably only through atomic nitrogen recombination on the catalytic sites, the nitrogen atoms being produced by $\mathrm{NH}_{\mathrm{x}}(3<x<1)$ dissociation either into the plasma bulk or at the interface.

From the above results, catalytic recombination processes seem to be simultaneous and then competitive to the nitriding phenomema. However, recombination processes will only compete with nitridation in the case where the nitriding process is controlled by active species flux, this occurs when the energetic density, the flow rate or the temperature is low. In all the other cases, recombination does not compete with diffusion, since the active species flux is high enough. But, due to the energy released during recombination processes, provoking an increase of the substrate temperature, recombination phenomena will enhance nitrogen diffusion into the titanium. 


\section{CONCLUSION}

A kinetics study of titanium nitride layers growth obtained under low pressure plasma conditions lead to a further understanding of the elementary phenomena responsible for the nitrogen transportation into the substrate. Nitrogen transport has been seen to be strongly depending on the electrical properties of the thin layers, present on top of the substrate. Thus, for a low temperature and/or a low plasma energetic density, the nitriding process is controlled by an electrically assisted nitrogen migration into a n-type semiconductive layer. While for higher temperatures and longer time, it is controlled by thermochemical diffusion mechanisms, since the superficial layer is continuously getting conductive properties as the nitrogen concentration is increasing. The CVP and the spectroscopic analyses of the plasma have pointed out that for a low active species flux, a competition between atomic nitrogen recombination and nitriding occurs. On the opposite, when the nitriding process is controlled by the nitrogen transport into the titanium, the recombination processes enhance the treatment, by acting as a energetic sink. Laser absorption spectroscopy strongly suggested that $\mathrm{NH}_{x}$ radicals are completely dissociated as they approach the surface and therefore the nitriding, under conditions where the substrate acts as a cathode, is due more probably to nitrogen atoms rather than $\mathrm{NH}_{X}$ radicals. Since our experimental set up was not designed to measure the ground state $\mathrm{N}_{2}{ }^{+}$ions concentrations, we cannot exclude their action as active species for nitridation and as surface heating species as well. Although they are very difficult to detect into the plasma bulk, spectroscopic analysis has evidenced their presence at the interface, and the ESCA analyses have strongly suggested that they are active in controlling the stoechiometry of the very superficial nitride.

Acknowledgements We are grateful to DRET for financial support of this work, to Dr. Dufour for the ESCA analyses, to Dr. Perriere, Dr. Moncoffre and Pr.Tousset for the RBS analyses, to Dr. Pivin for NRA analyses and to Dr. Lincot for the photoelectrochemical analyses.

\section{REFERENCES}

1. R. Juza , Adv. in Inorg. Chem. Radio Chem. 981 (1966)

2. L. E. Toth, Transition Metal Carbides and Nitrides, Academic Press, New York (1971)

3. J.E. Sundgren, B. O. Johansson, S. E. Karlson, H. T. G. Hentzell, Thin Solid Films, 105, 367, (1983)

4. B. Coll, P. Jacquot, Surface and Coatings Technology, 36, 867-878 (1988)

5. Y. Nakazaki, K.Suguro, S. Shima, M. Kashiwagi, I. Appl. Phys. 64 (6) (1988)

6. M.A. Nicolet, M. Bartur, I. Vac. Sci. Technol. 19 (3), 766 (1981)

7. A. Deneuville, Proc. 2 nd Coll. Nat. sur le Silicium, Paris (1987)

8. H. Michel, M. Gantois, 18th Intern. Conf. on Heat Treatment of Materials, USA (1980)

9. N. Iwamoto, Y. Makino, Y. Murakami, proc. ISPC8, Tokyo, 2 , 1166-1171 (1987)

10. V. Quichaud, D. Dézert, J. Aubreton, D. Degout, A. Catherinot, Laser Chem. 10, 93-117 (1989)

11. M. Konuma, O. Matsumoto, Y. Konzaki, I. of the Less Common Metals, 75, 1-5 (1980)

12. O. Matsumoto, Adv. in Low Temp. Plasma Chem. Techn.Lancaster 53 (1984)

13. P. Bradu, D. Degout, A. Gicquel, A. Ricard, Rev. Sci. et Tech. de la Défense, to be published (1990)

14. A. Ricard, H. Michel, M. Gantois, Rev. Int. Hautes Tempé Réfrac., 24, 119-128 (1988)

15. R. Avni, T. Spalvins, Mat. Science and Engineering, 95, 237-46 (1987)

16. J. P. Bars, E. Etchessahar, J. Deguigne, Proc. 6th World Conf. on Titanium, France, 1565-70 (1988)

17. A. E. Palty, H. Margolin, J. Nielsen, Trans. ASME, 46, 312 (1954)

18. J. P. Bars, E. Etchessahar, J. Deguigne, I. of the Less Common Metals, 52, $51-76$ (1977)

19. F. W. Wood, O. G. Paasche, Thin Solid Films 40 (1977) 131-137

20. P. G. Shewmon, Diffusion in Solids, McGraw-Hill, New York (1962 ou 63)

21. S. De Benedictis, A. Gicquel, F. Cramarossa Proc. ISPC8, Tokyo, 1 , 631 (1987)

22. M. Hudis, J. Appl. Phys. 44, 1489 (1973)

23. M. Massabiaux, G. Gousset, M. Lefèvre, M. Pealat, I. Phys. 48, 1939 (1987)

24. A. Ricard, A. Besner, J. Hubert, M. Moisan, I. Phys. B; At Mol. Opt Phys., L579-83 (1988)

25. K. Hassouni, S. Piétré, P. Saillard, A. Gicquel, J. Amouroux, ISPC9 to be published (1989)

26. N. Laidani, J. Perriere, D. Lincot, A. Gicquel, J. Amouroux, Appl. Surface Science, 36 , 520, (1989)

27. J. Benard, l'Oxydation des métaux tome 2, Gauthier-Villars, Paris (1964)

28. F. P. Felhner, N. F. Mott, Rep. Prog. Phys, 12, 163 (1949)

29. A. Gicquel, P. Saillard, N. Laidani, J. Amouroux, Rev. Phys. Appl. , 24; 285-294 (1989)

30. A. Gicquel, M. Cappelli, A. Chang, R. K. Hanson, Proc. ISPC 9, Italy to be published (1989) 